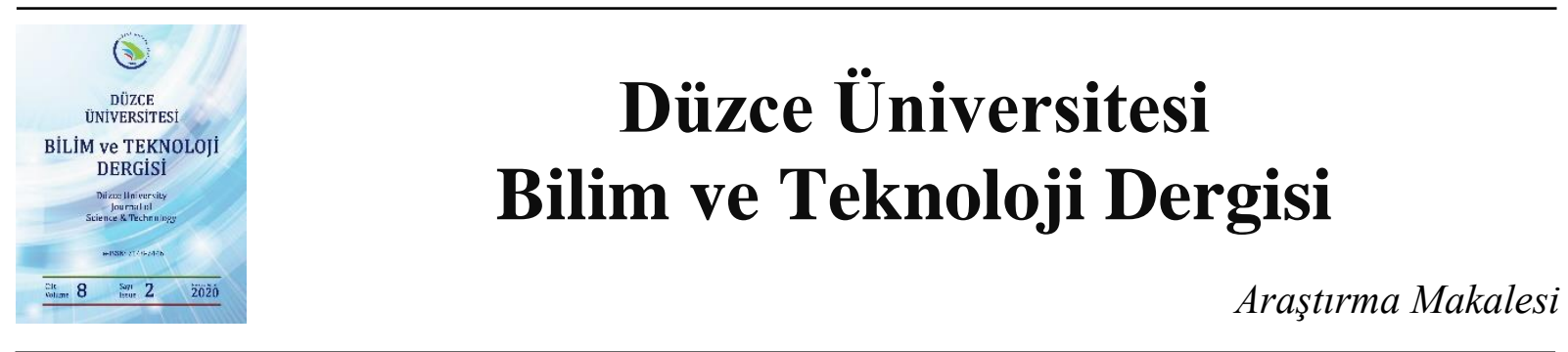

\section{Performans Bisiklet Lastiği Sırt Karışımının Geliştirilmesi ve Özelliklerinin İncelenmesi}

\author{
Gasim ALTUNDAL ${ }^{a}$, (iD Hüsnü GERENGi ${ }^{b}$, (iD Esra ÇETIN ${ }^{a}$, (iD Uğur KAPCAK ${ }^{\text {a }}$, (iD Kerem \\ KAYMAZ $^{\mathrm{a}}$ \\ ${ }^{a}$ Ar-Ge Merkezi, Anlas Anadolu Lastik Sanayii ve Ticaret A.Ş., Düzce, TÜRKIYYE \\ ${ }^{b}$ Makine Mühendisliği Bölümü, Mühendislik Fakültesi, Düzce Üniversitesi, Düzce, TÜRKIYE \\ * Sorumlu yazarin e-posta adresi: husnugerengi@gmail.com \\ DOI : 10.29130/dubited.698101
}

\begin{abstract}
ÖZET
Pnömatik lastik, zincir tahriki ve ardından dişli teknolojisindeki gelişimlerle birlikte, bisiklet sektöründe 1800 'lerin sonlarında başlayan büyük devrim günümüze kadar artarak devam etmektedir. Dökme demir ve ahşaptan oluşan ana gövde günümüzde; titanyum, alüminyum ve karbon fiber gibi malzemelerden yapılmaktadır. Bisiklette bulunan; fren, amortisör, sele, vites sistemi ve lastiğindeki gelişmeler bisikleti her zamankinden daha hafif ve daha sağlam bir konfor aracına dönüştürmüştür. İçten yanmalı motorlu araçların neden olduğu çevre kirliliğini arttırması ve bisiklet kullanımının çağımızın hastalıkları olarak bilinen; inme, kalp krizi, depresyon, diyabet, obezite ve artrit gibi ciddi sağlı problemlerine çözüm olabileceğine dair ortaya konulan bilimsel gerçeklikler, bisiklet sektörünün daha da gelişeceğinin birer kanıtıdır. Kuru, sslak veya çamurlu yollarda, sürüş hızına bağlı olarak iyi manevra ve frenleme kabiliyeti için bisiklet lastiği sırt hamuru karışımı üzerine yoğun çalışmalar yapılmaktadır. Bu çalışmada, TÜBİTAK-1501 (Proje No: 3180325) projesi kapsamında üretilen katlanabilir performans lastiği için geliştirilen sırt hamur karışımının reolojik ve fiziko-mekaniksel özellikleri incelenmiştir.
\end{abstract}

Anahtar Kelimeler: Bisiklet lastiği, Bisiklet sırt karışımı, MDR, TGA, RPA

\section{Improvements of the Performance Bicycle Tire Tread Compound and Examination of Its Properties}

\begin{abstract}
With the advances in pneumatic tire, chain drive and then gear technology, the great revolution in the bicycle industry that began in the late 1800s has been increasing to the present day. The main body consisting of cast iron and wood today; it is made from materials such as titanium, aluminium and carbon fiber. Improvements in the brake, dashpot, saddle, gear system and tyre on the bike have transformed the bike into a lighter and more robust comfort vehicle than ever before. Environmental pollution caused by internal combustion motor vehicles to increase bicycle use and the disease of our age known as; scientific facts revealed that it can be a solution to serious health problems such as stroke, heart attack, depression, diabetes, obesity and arthritis are evidences that the bicycle industry will develop further. On dry, wet or muddy roads, intensive studies are carried out on the bicycle tire tread pulp mixture for good manoeuvrability and braking ability, depending on the speed of driving. In this study, the rheological and physico-mechanical properties of the tread compound developed for the
\end{abstract}




\section{GIRIS}

Fosil yakıtlar bugün dünyada kullanılan başlıca enerji kaynaklarından biridir. Enerji çeşitliliğine rağmen günümüzde hala ham petrol, fosil enerjisinin yaklaşı \%39'unu oluşturan en büyük enerji kaynağıdır. Bunu sırasıyla \%33 ve \%28 oranla kömür ve doğal gaz takip etmektedir (Şekil 1) [1]. Ancak aşırı fosil yakıtı tüketiminin, hava kirliliği gibi ciddi çevresel sorunlara yol açtı̆̆ artık bilimsel olarak kanıtlanmıştır. Fosil yakıtların kullanımına bağlı olarak havaya salınan karbondioksit, azot dioksit, kükürt dioksit, kükürt trioksit, karbon monoksit gibi gazlar asit yağmurlarına neden olmaktadır Eşitlik 1-4 [2,3]:

$$
\begin{aligned}
& \mathrm{SO}_{2(\mathrm{~g})}+\mathrm{H}_{2} \mathrm{O}_{(\mathrm{s})} \rightarrow \mathrm{H}_{2} \mathrm{SO}_{3(\mathrm{aq})} \\
& 2 \mathrm{SO}_{2(\mathrm{~g})}+\mathrm{O}_{2(\mathrm{~g})} \rightarrow 2 \mathrm{SO}_{3(\mathrm{~g})} \\
& \mathrm{SO}_{3(\mathrm{~g})}+\mathrm{H}_{2} \mathrm{O}_{(\mathrm{s})} \rightarrow \mathrm{H}_{2} \mathrm{SO}_{4(\mathrm{aq})} \\
& 2 \mathrm{NO}_{2(\mathrm{~g})}+\mathrm{H}_{2} \mathrm{O}_{(\mathrm{s})} \rightarrow \mathrm{HNO}_{2(\mathrm{aq})}+\mathrm{HNO}_{3(\mathrm{aq})}
\end{aligned}
$$

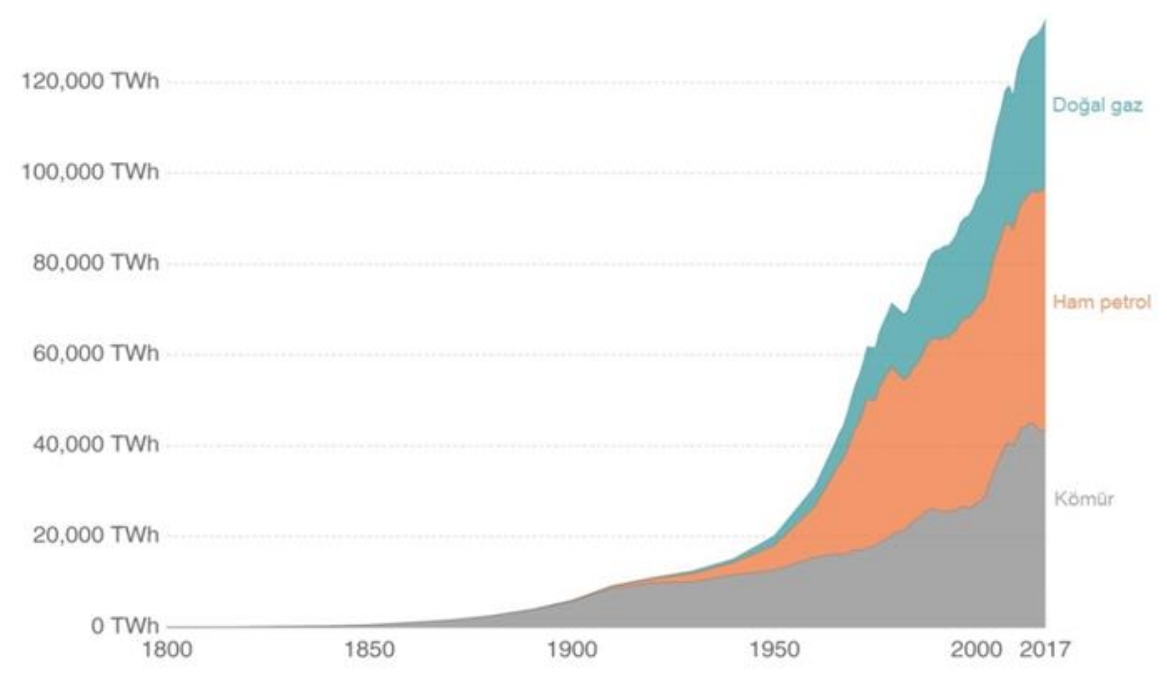

Şekil 1. Küresel fosil yakıtı tüketimi (TWh: Terawatt-saat).

Canlı yaşamını da önemli ölçüde etkileyen bu ciddi problemin maalesef daha da çok artacağı öngörülmektedir [4]. Tarih öncesi fosillerden elde edilen bu kaynakların, yakıt olarak değil de farklı alanlarda (plastik, tekstil, ilaç, kozmetik, vb.) kullanılması gerektiğini belirten çalışmalar bulunmaktadır $[5,6]$.

Özellikle egzoz emisyonlarının neden olduğu çevre kirliliğini azaltmak için bazı gelişmiş bazı Avrupa ülkeleri (Birleşik Krallık, Fransa, Almanya, İrlanda ve Norveç) 2040 yılına kadar benzin ve dizel 
araçların kullanımını yasaklamayı planlamaktadırlar [7]. Bu mücadele elektrikli araçların ve 1800'lü yılların sonunda hayatımıza giren bisikletin yaygınlaştırılmasıyla daha anlamlı hale gelmektedir (Şekil 2) $[8,9]$. Nispeten basit bir makine olan bisiklet [10], diğer enerji kaynaklarına göre çok daha verimlidir [11]. Bisiklet gibi motorsuz ulaşım araçları; kentsel tıkanıklığı, kirliliği, kazaları azaltma ve az hareketlilik nedeniyle insan sağlığını önemli ölçüde olumsuz etkileyen obeziteye çözüm olarak önerilen en önemli çözüm yöntemdir [12].

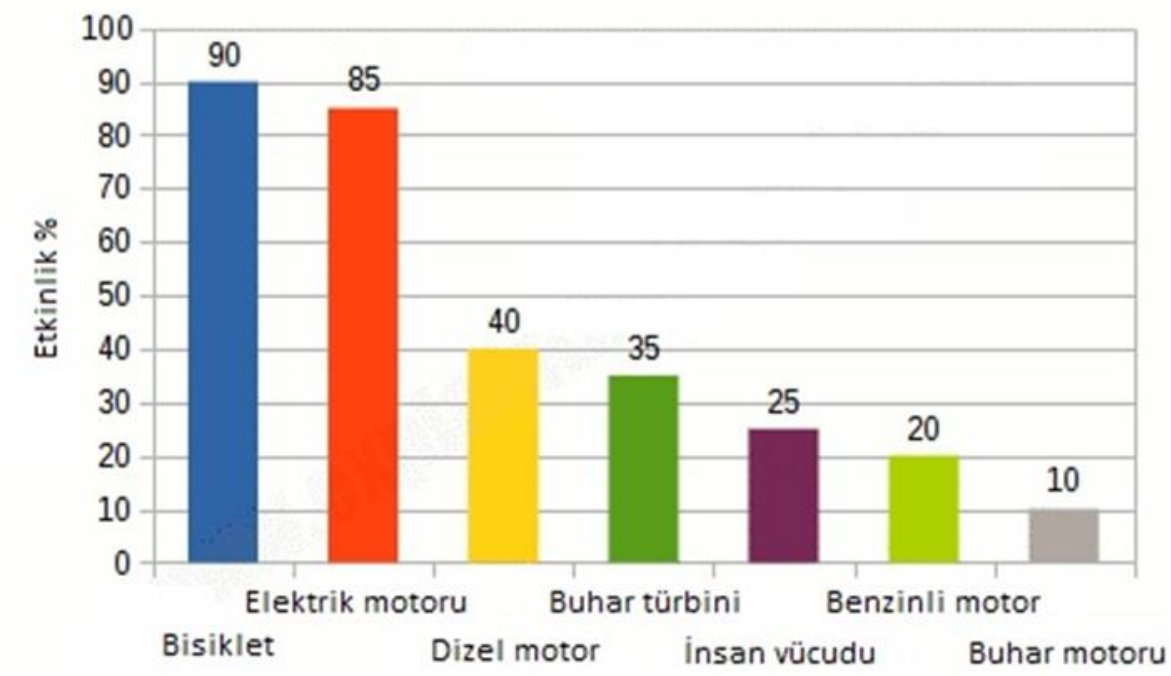

Şekil 2. Enerji veriminin kıyaslanması.

Bisiklet kullanımını teşvik etmek için gelişmiş ülkeler ve ABD'deki birçok eyalet, son yirmi yılda bisiklet sistemini iyileştirmek için ciddi ekonomik yatırımlar yapmaktadırlar [13]. Bu bağlamda bisiklet paylaşım sistemleri (Bicycle Sharing Systems [BSS]) yaygınlaştırılmaktadır [14].

Lastik, bisikletin en önemli bileşenidir. Hareketi sağlayan, bisikletle yol arasındaki tek bağlantı noktası olan bu ana bileşenin, daha güvenli sürüş sağlaması için darbe ve delinmelere karşı dayanıklı olması son derece önemlidir [15].

Bu çalışmada, katlanabilir özelliğe sahip yüksek performans bisiklet lastiği [16] için üretilen üç farklı bisiklet lastiği sırt karışımının reolojik ve fiziko-mekaniksel özellikleri incelenmiş ve en uygun sırt karşımı seçilmiştir.

\section{MATERYAL VE METOT}

\section{A. MATERYAL}

Reçetelerde doğal kauçuk olarak SMR 20 (Standart Malezya Kauçuk), sentetik kauçuk olarak Stiren Bütadien Kauçuk 1502 ve SBR 1723, dolgu maddesi olarak N220 karbon siyahı ve kalsit, proses yağ1 olarak da naftanik yağ kullanılmıştır. Reçete dizaynında belirlenen adımlar doğrultusunda [17], 3 farklı reçete ürün oluşturulmuştur. Reçeteler ve kullanılan kimyasalların (Parts Per Hundred Rubber : phr) "phr" cinsinden miktarları Tablo 1'de verilmiştir. Reçetelere, karışım 1, 2 ve 3 isimleri (K1, K2 ve K3) verilmiştir. 
Tablo 1. Dizayn edilen bisiklet lastiği sırt karışımı reçeteleri.

\begin{tabular}{lccc}
\hline Hammaddeler (phr) & Karışım 1 (K1) & Karışım 2 (K2) & Karışım 3 (K3) \\
\hline Doğal kauçuk & $20 \pm 2$ & $20 \pm 2$ & $35 \pm 3$ \\
\hline SBR 1723 & - & $110 \pm 2$ & $68,75 \pm 2$ \\
\hline SBR 1502 & $35 \pm 3$ & - & - \\
\hline Rejenere kauçuk (NR Bazlı) & $90 \pm 2$ & - & $30 \pm 3$ \\
\hline N220 & $28 \pm 2$ & $65 \pm 2$ & $65 \pm 2$ \\
\hline Naftanik yağ & $3 \pm 0,3$ & $4 \pm 0,4$ & $7 \pm 0,5$ \\
\hline CaCO & $10 \pm 1$ & - & - \\
\hline ZnO & $5 \pm 0,5$ & $3 \pm 0,3$ & $3 \pm 0,3$ \\
\hline CH3(CH$)_{\mathbf{1 6}}$ COOH & $1 \pm 0,2$ & $2 \pm 0,2$ & $2 \pm 0,2$ \\
\hline 6PPD & $1 \pm 0,2$ & $2,5 \pm 0,25$ & $2,5 \pm 0,25$ \\
\hline P.WAX & - & $1 \pm 0,2$ & $1 \pm 0,2$ \\
\hline TMQ & $1,5 \pm 0,2$ & $1 \pm 0,2$ & $1 \pm 0,2$ \\
\hline M.WAX & $1,5 \pm 0,2$ & $3 \pm 0,3$ & $3 \pm 0,3$ \\
\hline Reçine & $1,5 \pm 0,2$ & $2 \pm 0,2$ & $7 \pm 0,5$ \\
\hline S & $2 \pm 0,25$ & $2,4 \pm 0,25$ & $2,4 \pm 0,2$ \\
\hline CBS & $0,95 \pm 0,1$ & $1,1 \pm 0,2$ & $1,1 \pm 0,2$ \\
\hline MBTS & $0,25 \pm 0,1$ & - & - \\
\hline DPG & - & $0,4 \pm 0,1$ & $0,4 \pm 0,1$ \\
\hline
\end{tabular}

Ana kademe ve son kademe hamurlarının hazırlanmasında banbury tipi karıştırıcı kullanılmıștır (Şekil $3)$.

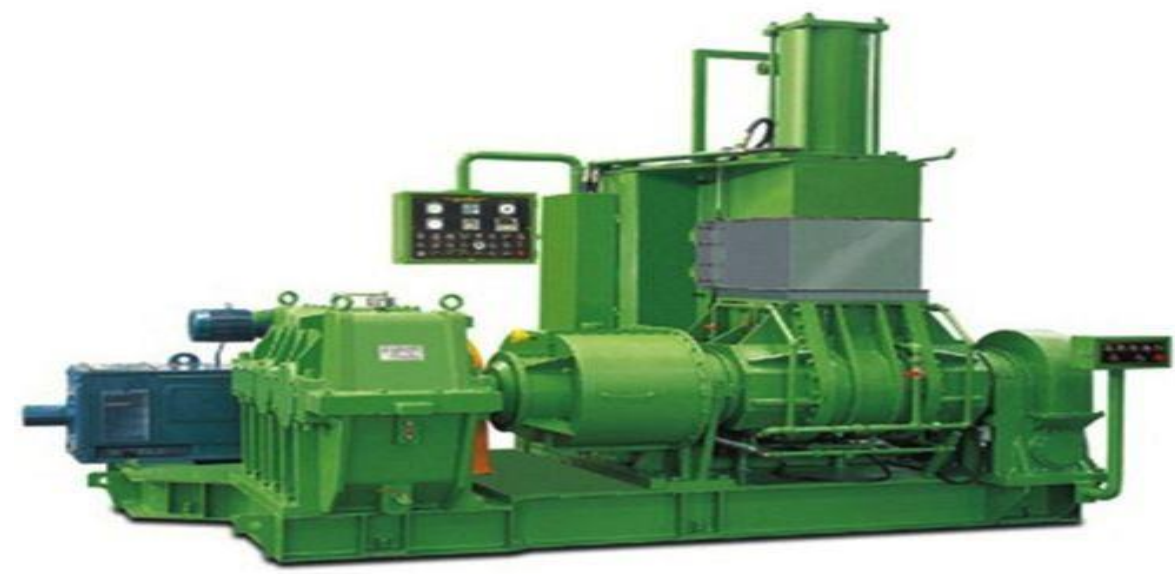

Şekil 3. Banbury tipi karıştırıcı

Ana kademede kauçuklar, dolgu maddeleri, proses yağları, antidegredantlar, aktivatörler ve reçineler eklenerek karıştırma işlemi yapılmıştır. Son kademede ise pişiriciler adı verilen kimyasal grup (vulkanizasyon ajanı ve akselaratörler) eklenerek karışım hazır hale getirilmiştir. Karışımların hazırlanma adımları Tablo 2 'de süreleri ile birlikte verilmiştir. 
Tablo 2. Lastik hamuru hazırlama adımları.

\begin{tabular}{ll}
\hline Ana kademe & Süre $(\boldsymbol{d} \boldsymbol{k})$ \\
\hline Kauçuklar + Kimyasallar & 0 \\
\hline Dolgu maddeleri + Proses yağları & $0,8-1,0$ \\
\hline Havalandırma & 2,5 \\
\hline Boşalt & 6 \\
\hline Son kademe & Süre $(\boldsymbol{d} \boldsymbol{k})$ \\
\hline Ana kademe karışımı & 0 \\
\hline Pişiriciler & $0,5-1$ \\
\hline Havalandırma & 1,5 \\
\hline Boşalt & 3 \\
\hline
\end{tabular}

\section{B. METOT}

\section{B. 1. Yoğunluk ve Sertlik Testi}

Yoğunluk testi, katı cisimlerin yoğunluğunu ölçmeye yönelik tasarlanmış Mettler Toledo yoğunluk ölçme kiti ile yapılmıştır (Şekil 4). Sertlik testi ASTM D2240'a göre Mitutoyo Shoremetre cihazı ile (Shore A cinsinden) yapılmıştır.

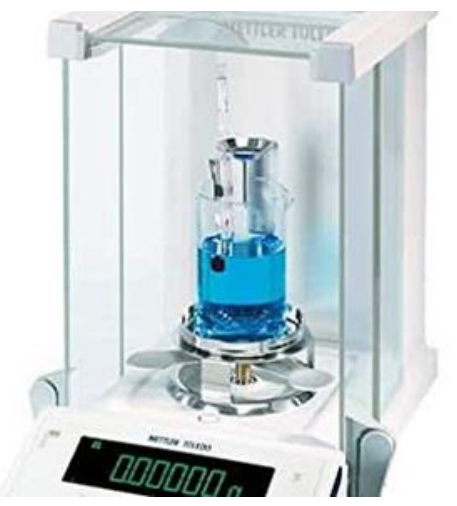

Şekil 4. Mettler Toledo yoğunluk ölçme kiti

\section{B. 2. Fiziko-mekaniksel Testler}

Fiziko-mekaniksel testler $170{ }^{\circ} \mathrm{C}^{\prime}$ de 10 dakika preste pişirilerek hazırlanan plakadan papyon numuneler kesilerek yapılmıştır. Kopma, uzama ve \%300 modulus testleri ASTM D412'ye göre EKTRON- TS-2000 marka Çekme Test Cihazı ile yapılmıştır (Şekil 5). Papyon numunelerin NÜVE marka etüvde $100{ }^{\circ} \mathrm{C}$ 'de 72 saat bekletilmesi ile yaşlandırılması sağlanmış, sonrasında aynı fizikomekaniksel testler yapılmıştır. 


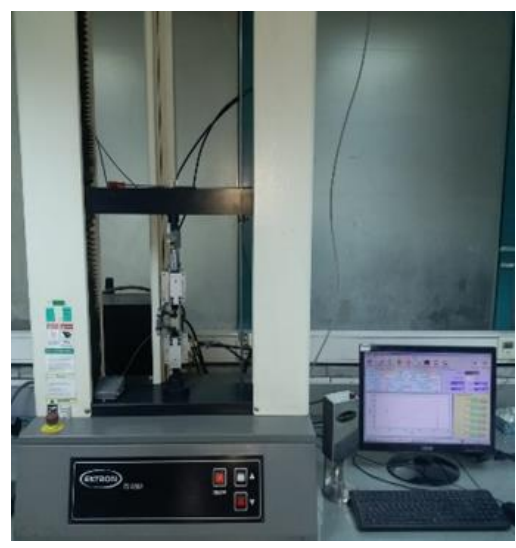

Şekil 5. EKTRON TS 2000

\section{B. 3. Reolojik Testler}

Reometre testleri (Moving Die Rheometer, MDR), EKTRON MDR 2000S ile ASTM D5289 standardına göre $195^{\circ} \mathrm{C}^{\prime}$ de 5 dakika olarak yapılmıştır (Şekil 6).

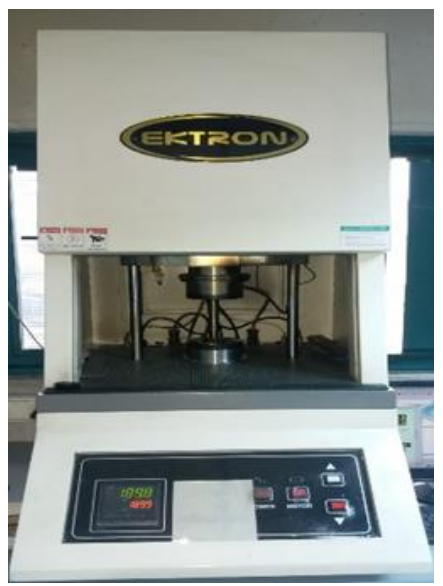

Şekil 6. EKTRON MDR 2000S

Mooney Scorch (SC) testleri, ASTM D1646 standardına göre $135^{\circ}{ }^{\circ}$ 'de EKTRON MV 2001M cihazı ile yapılmıştır (Şekil 7).

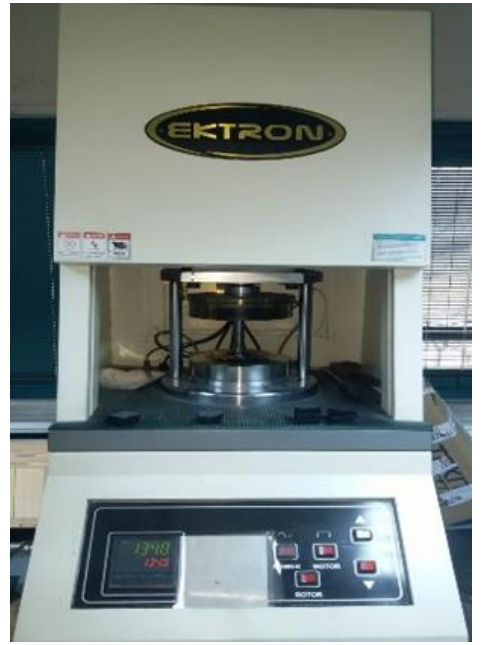

Şekil 7. EKTRON MV 2001M 
Karışımların proses ve elastiklik özellikleri hakkında bilgi edinebilmek için Rubber Process Analyzer (RPA) testi yapılmıştır (Şekil 8). Standard Profil A.Ş. ürün test standartlarına uygun [18], sırasıyla aşağıda belirtilen sıcaklıklarda ilgili parametreler 3 aşamada bulunmuştur;

- $\quad 90{ }^{\circ} \mathrm{C}$ de, $\% 0,5$ gerinim (strain) de frekans taraması yapılarak hamurun kayması (shear ile) değişen $\mathrm{n}^{*}$ (intrinsic viscosite) in bulunması,

- $\quad 190^{\circ} \mathrm{C}$ de $1,7 \mathrm{~Hz}$ de $\% 7$ gerinim de hamurun pişirilip pişme (cure) özelliklerinin bulunması,

- $\quad 50{ }^{\circ} \mathrm{C}$ de $1 \mathrm{~Hz}$ de gerinim taraması yapılarak tanD değeriyle elastisik özellikleri hakkında bilgi edinilmesi (küçük olan en elastik olanıdır).

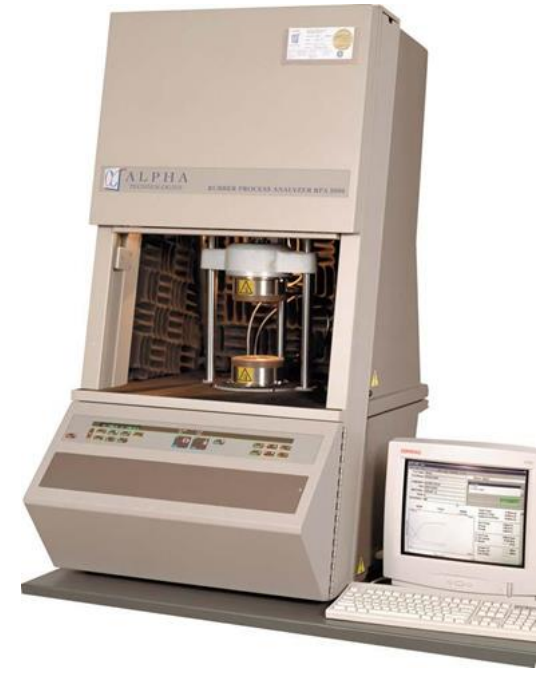

Şekil 8. ALPHA RPA

\section{B. 4. Termogravimetrik Analiz (TGA)}

Karışımların termal bozulma karakteristikleri, TA Instruments Q500 marka termogravimetrik analiz (TGA) cihazı ile yapılmıştır (Şekil 9). Oda sıcaklığından $600^{\circ} C^{\prime}$ ye kadar $\mathrm{N}_{2}$ ile ssıtıp, $600{ }^{\circ} \mathrm{C}$ 'den 800 ${ }^{\circ} \mathrm{C}^{\prime}$ ye kadar $\mathrm{O}_{2}$ 'le muamele edilmiştir. Isıtma hızı $10{ }^{\circ} \mathrm{C} /$ dak'dır.

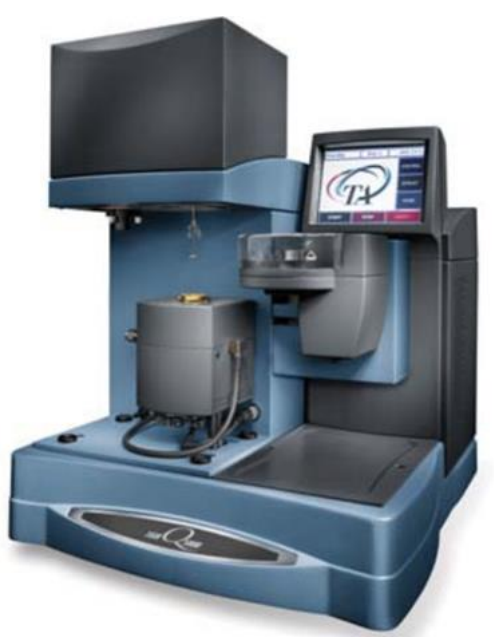

Şekil 9. TGA cihazı 


\section{BULGULAR VE TARTISMA}

\section{A. KULLANILAN YÖNTEMLERDEN ELDE EDILEN SONUÇLAR}

\section{A. 1. Yoğunluk ve Sertlik Testi}

Tablo 1'de belirtilen reçete ile hazırlanan hamurlardan elde edilen numunelere 7 kez yoğunluk ve sertlik testi yapılmış ve sonuçların ortalaması Tablo 3'te belirtilmiştir.

Tablo 3. Numunelerin yoğunluk ve sertlik değerleri.

\begin{tabular}{ccc}
\hline Numune & $\begin{array}{c}\text { Yoğunluk } \\
\left(\mathrm{g} / \mathrm{cm}^{3}\right)\end{array}$ & $\begin{array}{c}\text { Sertlik } \\
(\text { Shore } A)\end{array}$ \\
\hline $\mathrm{K} 1$ & 1,162 & 62 \\
\hline $\mathrm{K} 2$ & 1,123 & 61 \\
\hline $\mathrm{K} 3$ & 1,135 & 62 \\
\hline
\end{tabular}

Hazırlanan üç karışımın birbirine son derece yakın sertliklere sahip olduğu görülmektedir. K1 ve K3 numunelerinin 62 Shore A değeri ile aynı sertlikte, K2 numunesinin de 61 Shore A değeri ile 1 birim daha yumuşak olduğu görülmektedir. Yoğunluk, karışımın birim hacimdeki ağırlığını göstermektedir ve lastiğin ağırlığını belirleyen parametredir. Lastiğin hafif olması taşıma ve sürüş sırasındaki güç tasarrufu açısından önemli olduğu için hafif sırt karışımı tercih edilmelidir. Ancak K1 numunesinin yoğunluğunun sırasiyla K2 numunesinden $\% 3.35$, K3 numunesinden $\% 2.32$ daha yüksek olduğu görülmektedir. Katlanabilir özelliğe sahip yüksek performans bisiklet lastiklerinin diğer lastik türlerine göre daha hafif olması beklenmektedir. Dolayısıyla K2 numunesinden yapılmış lastiğin daha kolay katlanabilir ve daha hafif olacağı görülmektedir.

\section{A. 2. Fiziko-mekaniksel ve Reolojik testler}

Hazırlanan 3 farklı bileşime sahip numuneye (K1,K2 ve K3), 4 ana test yapılarak 13 adet parametre için veri elde edilmiştir. Elde edilen veriler Tablo 4'te verilmiştir.

ASTM D573-04'ye göre hazırlanan K1, K2 ve K3 numuneleri yaşlandırma işlemine tabi tutulmuştur. Elde edilen kopma dayanımı, yüzde uzama, \%300 Modulus ve sertlik değerleri yaşlandırma öncesi değerlerle kıyaslanmıştır.

Tablo 4. Sırt karışımlarına ait test sonuçları.

\begin{tabular}{|c|c|c|c|c|}
\hline Test Parametreleri & & K1 & K2 & K3 \\
\hline \multirow{4}{*}{$\begin{array}{l}\text { MDR } \\
\text { (a) } 195{ }^{\circ} \mathrm{C}, 3 \mathrm{~min}\end{array}$} & ML (dNm) & 2,1 & 2,2 & 2,3 \\
\hline & MH (dNm) & 9,9 & 11,6 & 11,7 \\
\hline & $\mathbf{t}_{\mathrm{s} 2}(\mathrm{dk}: \mathrm{sn})$ & $00: 29$ & $00: 39$ & $00: 31$ \\
\hline & $t_{90}(d k: s n)$ & $00: 51$ & $01: 27$ & 01:00 \\
\hline \multirow{2}{*}{$\begin{array}{l}\text { MOONEY } \\
@ 135^{\circ} \mathrm{C}\end{array}$} & ML (MU) & 42,46 & 46,39 & 45,09 \\
\hline & $\mathbf{t}_{5}(\mathrm{dk}: \mathrm{sn})$ & $10: 48$ & $17: 32$ & $14: 56$ \\
\hline \multirow{3}{*}{$\begin{array}{l}\text { Fiziksel özellikler } \\
@ 170{ }^{\circ} \mathrm{C}, 5 \mathrm{~min}\end{array}$} & Kopma dayanımı $\left(\mathrm{kg} / \mathrm{cm}^{2}\right)$ & 115 & 160 & 150 \\
\hline & Uzama (\%) & 450 & 615 & 490 \\
\hline & \%300 Modulus (kg/cm²) & 73 & 55 & 80 \\
\hline \multirow{4}{*}{$\begin{array}{l}\text { Yaslandırma sonrası } \\
\text { fiziksel özellikler } \\
\text { @ } 170{ }^{\circ} \mathrm{C}, 5 \mathrm{~min}\end{array}$} & Kopma dayanımı $\left(\mathrm{kg} / \mathrm{cm}^{2}\right)$ & 125 & 160 & 150 \\
\hline & Uzama $(\%)$ & 310 & 465 & 390 \\
\hline & \%300 Modulus (kg/cm²) & 90 & 93 & 110 \\
\hline & Sertlik (Shore A) & 67 & 64 & 67 \\
\hline
\end{tabular}


ML değerleri, karışımın en düşük viskozite değerlerini vermektedir. Bu değer karışımın prosesteki akma davranışının nasıl olacağı hakkında bilgi vermektedir. Hazırlanan 3 karışımın da viskozite değerleri 2,1 ile 2,3 $\mathrm{dNm}$ aralığında birbirine yakın değerdedir.

MH değerleri, karışımın vulkanizasyon sonrasındaki en yüksek viskozite değerini vermektedir. Kauçuk numunelerin birleşiminde bulunan karbon veya pişiricilerin $\mathrm{MH}$ değerini etkilediği bilinmektedir. K2 ve K3 karışımlarının MH değerleri 11,6-11,7 dNm aralığında birbirine yakındır. K1 karışımının MH değeri diğer numunelere kıyasla yaklaşık 1,7 birim daha düşüktür.

ts2 değeri, karışımın vulkanize olmaya başladığı süredir. K1 ve K3 karışımlarının ts2 değerleri aynı iken K2 karışımının ts2 değeri, diğerlerine kıyasla 9 saniye daha fazladır. Bu değerin yüksek olması proseste karışımın scorch (mini yanık) oluşturma ihtimalini düşürmektedir.

t90 değeri, karışımın \%90 vulkanize (pişme) olması için gerekli süredir. Bu değer pişme süresi ile birlikte birim zamanda üretilebilecek lastik adeti hakkında fikir vermektedir. K1 karışımının pişme süresi en düşük iken (51 saniye), K2 karışımın t90 değeri 87 saniyedir. Dolaysıyla K2 karışımına sahip numunesinin 190 değeri, $\mathrm{K} 1$ numunesine kıyasla 36 saniye daha fazladır.

Mooney testinde elde edilen ML değeri, MDR analizindeki ML değeri ile benzer ancak birim olarak farklıdır. K1 numunesinin ML değerinin, MDR analizindeki ML değeri gibi en küçük olduğu görülmüştür. K1, K2 ve K3 numunelerin ML değerlerinin 42,46 ile 46,39 MU arasında birbirine yakın değerlerde olduğu Tablo 4'te görülmektedir. t5 değeri; minimum viskozite değerinden 5 birim yükseldiği süreyi göstermektedir [20]. MDR de ölçülen ts2 değeri ile benzer bir parametredir. Karışımın pişmeye başladığı zamanı da ifade eden bu değerin en yüksek olduğu numunenin K2 olduğu görülmektedir.

Kopma dayanımı, malzemenin kopması için gerekli kuvveti göstermektedir. K2 ve K3 karışımlarının kopma mukavemeti değerleri birbirine yakın ve K1 karışımından yaklaşık olarak $40 \mathrm{~kg} / \mathrm{cm}^{2}$ daha yüksektir.

Uzama yüzdesi değeri sırasıyla $\mathrm{K} 2>\mathrm{K} 3>\mathrm{K} 1$ şeklindedir. K3 ve $\mathrm{K} 1$ numuneleri arasındaki uzama yüzdesi fark1 40 birimdir. Bu fark kabul edilebilir aralıktadır. K2 numunesinin uzama yüzdesi K1 numunesinden 165 birim daha yüksektir. Malzemenin uzama yüzdesi, elastikiyet özelliğinin bir göstergesidir. Ancak direkt veya dolaylı etkilerle oluşan muhtemel kuvvetlerin etkisiyle elde edilen uzama yüzdesi değeri, janttan kurtulma gibi istenmeyen bir olaya neden olabilir.

Modulus \%300 değeri, karışımın \% 300 uzamaya ulaşması için gerekli kuvvettir. Lastik dişlerinin esneme kabiliyeti olarak düşünülebilir. Modulus \%300 değeri; özellikle performans bisikletlerinin sürüş konforu için önemli bir parametredir. K3 numunesinin sırasıly K1 ve K2'den daha büyük modülüs değerine sahip olduğu görülmektedir.

Yaşlandırma işlemi sonunda ürünün fiziksel özelliklerinde minimum değişiklik olması beklenmektedir. ASTM D573-04 standardına göre yapılan yaşlandırma işlemi sonunda K2 ve K3 numunelerinin kopma dayanımında değişiklik olmamışken, K1 numunesinde $10 \mathrm{~kg} / \mathrm{cm}^{2}$ artış olduğu görülmektedir. Yaşlandırma işleminin elastikiyeti azalttığı bilinmektedir [19]. Nitekim üç numeninin de uzama yüzdelerinde azalma olduğu görülmektedir. Uzama yüzdesi değerinde en fazla azalma sırasıyla K2, K1 ve K3 numunesinde olmuştur. K3 numunesinde yaşlanma işleminin etkisiyle uzama yüzdesinde 100 birim azalma olmuştur. Yaşlanma işleminin, modulus \%300 değerlerini değiştirdiğini Tablo 4'teki ilgili verilerden görmekteyiz. Ancak K3 numunesinin yaşlanma öncesinde olduğu gibi en yüksek modulus $\% 300$ değerine $110 \mathrm{~kg} / \mathrm{cm}^{2}$ ile sahip olduğu görülmektedir. 
Tablo 5. RPA analizi.

\begin{tabular}{|c|c|c|c|}
\hline Freq02 $\left(90{ }^{\circ} \mathrm{C} ; \% 0.5\right.$ strain $)$ & K1 & $\mathbf{K 2}$ & K3 \\
\hline $0.1 \mathrm{~Hz} \mathrm{n}^{*}$ Pa.s & 395560 & 570170 & 582108 \\
\hline $8.33 \mathrm{~Hz} \mathrm{n} *$ Pa.s & 12697 & 18744 & 18472 \\
\hline $16.55 \mathrm{~Hz} \mathrm{n}^{*}$ Pa.s & 7254 & 10457 & 10247 \\
\hline $24.78 \mathrm{~Hz} \mathrm{n}^{*} \mathrm{~Pa} . \mathrm{s}$ & 5163 & 7354 & 7240 \\
\hline $33.00 \mathrm{~Hz}$ n* Pa.s & 4120 & 5808 & 5804 \\
\hline \multicolumn{4}{|c|}{ Cure03 $\left(90{ }^{\circ} \mathrm{C}-190^{\circ} \mathrm{C} ; 1.70 \mathrm{~Hz} ; \% 7\right.$ strain $)$} \\
\hline $\mathrm{S}^{\prime} @ \mathrm{Max} \mathrm{S}^{\prime}(\mathrm{MH})$ & 7,77 & 10,42 & 10,09 \\
\hline $\mathrm{S}^{\prime} @$ Min S'(ML) & 2,16 & 2,18 & 2,30 \\
\hline Time@90\% cure $\mathrm{S}^{\prime}$ & 2,65 & 3,30 & 2,66 \\
\hline $\operatorname{tanD@Max} \mathrm{S}^{\prime}(\mathrm{MH})$ & 0,12 & 0,09 & 0,10 \\
\hline Time@2 dNm scorch & 2,08 & 2,27 & 2,05 \\
\hline \multicolumn{4}{|l|}{ Strain04 $\left(50{ }^{\circ} \mathrm{C} ; 1.0 \mathrm{~Hz}\right.$ freq $)$} \\
\hline Angle $\% 1 ; \tan \mathrm{D}$ & 0,21 & 0,19 & 0,20 \\
\hline Angle \% $10 ; \tan \mathrm{D}$ & 0,25 & 0,23 & 0,24 \\
\hline Angle $\% 100 ; \tan \mathrm{D}$ & 0,36 & 0,25 & 0,32 \\
\hline
\end{tabular}

Gelişmiş bir test cihazı olan RPA, polimerik malzemenin dinamik mekanik özelliklerini; frekans, gerinim ve sıcaklık değişkenleri ile belirlemek için kullanılmaktadır. RPA ile malzemenin Freq02 testinde viskozite değerleri, cure03 testinde pişirme değerleri ve Strain04 testinde elastikiyet özellikleri Tablo 5'te gösterilmiştir. Freq02 ve cure03 testleri Mooney ve MDR testlerini simule etmektedir. Sabit gerinimde $90{ }^{\circ} \mathrm{C}$ de frekans $0.1 \mathrm{~Hz}$ 'ten $33 \mathrm{~Hz}$ 'e doğru arttıkça K1, K2 ve K3 numunelerinin viskozite değerleri azalmaktadır. K2 ve K3 numunelerindeki değişimin birbirine yakın ve K1'den büyük olduğu görülmektedir. Cure 03 verileri ile Tablo 4'te belirtilen $\mathrm{MH}, \mathrm{ML}$, 90 ve ts2 değerleri birbirini desteklemektedir. K3 numunesinin $\mathrm{S}^{\prime} @ M a x \mathrm{~S}^{\prime}(\mathrm{MH})$ değeri sirasıyla K2 ve K1 numunesinden büyüktür. MH-ML farkı çapraz bağlanma yoğunluğu hakkında bilgi verir. K1 numunesinde $\mathrm{MH}-\mathrm{ML}$ fark1 en azdır $(\mathrm{MH}-\mathrm{ML}=5.61)$. Bu fark en fazla 8.24 değeri ile $\mathrm{K} 2$ numunesinde olduğu belirlenmiştir. Time@2 dNm scorch verisi K2 numunesinin en geç pişen numune olduğunu belirtmektedir. Strain04 testi $50^{\circ} \mathrm{C}$ 'de kauçuk malzemenin sırasıyla \%1, 10 ve 100 açı ile 1 $\mathrm{Hz}$ frekansta uygulanan gerinim ile ölçülen elastikiyet değerlerini vermektedir. Tüm açılar için uygulanan gerinimlerde K2 numunesinin sirasıyla K3 ve K1 numunelerine göre daha elastik özellikte olduğu görülmektedir.

\section{A. 3. Termogravimetrik Analiz (TGA)}

TGA yöntemi; incelenen numunenin bir atmosferdeki kütlesinin, sıcaklık veya zamanın fonksiyonu olarak sıcaklığa karşı kaydedilmesiyle, kütlenin veya kütle yüzdesinin, zamana, sıcaklığa ve atmosferdeki değişime karş1 grafiğini çizmemize olanak sağlar. Bu çalışmada incelenen K1, K2 ve K3 numunelerinin termogramları Şekil 10-13'te gösterilmiştir. Ayrıca Şekil 14'te üç numune üst üste konularak karşılaştırılmıştır. 


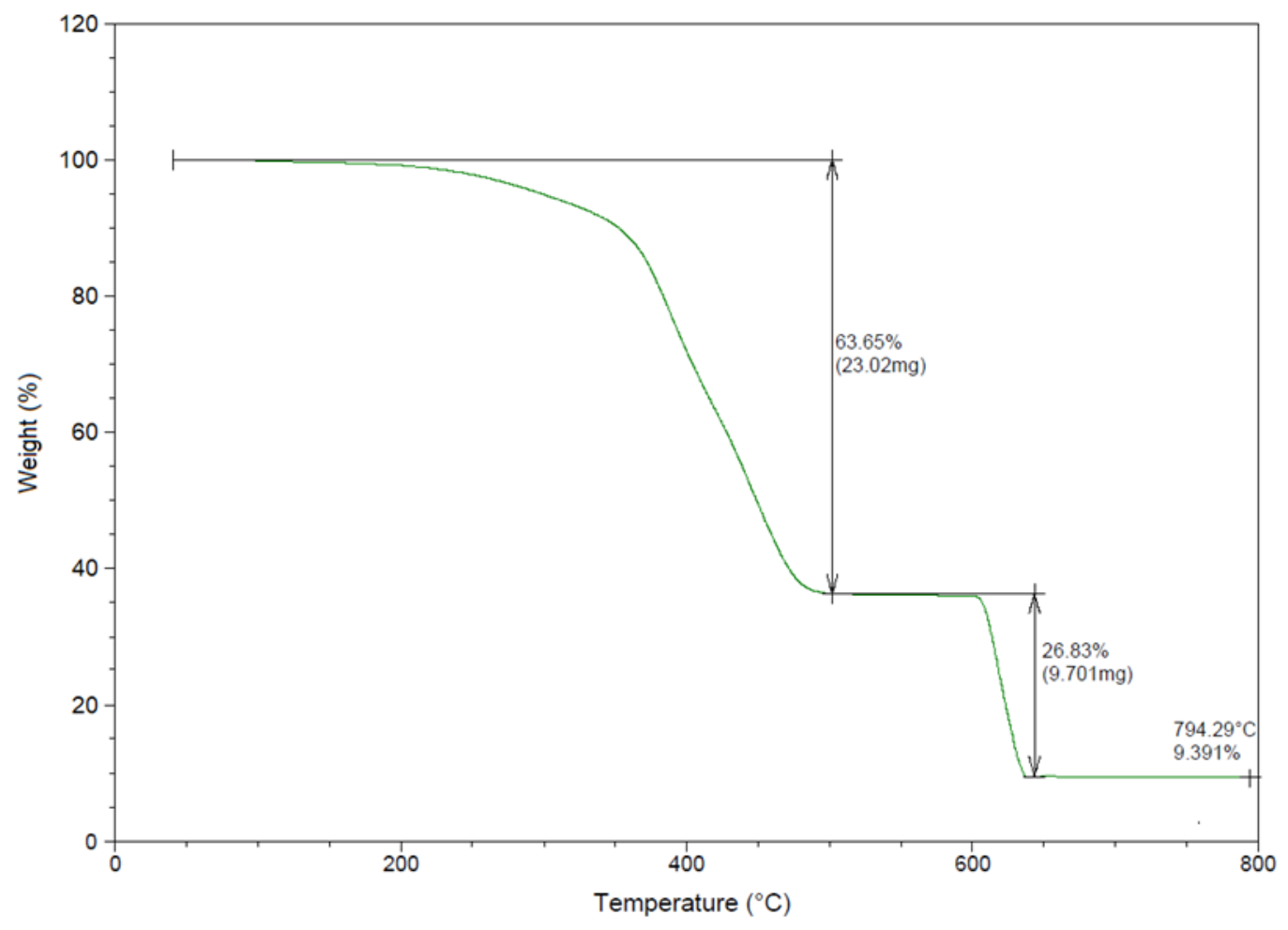

Şekil 10. K1 numunesinin termogramı

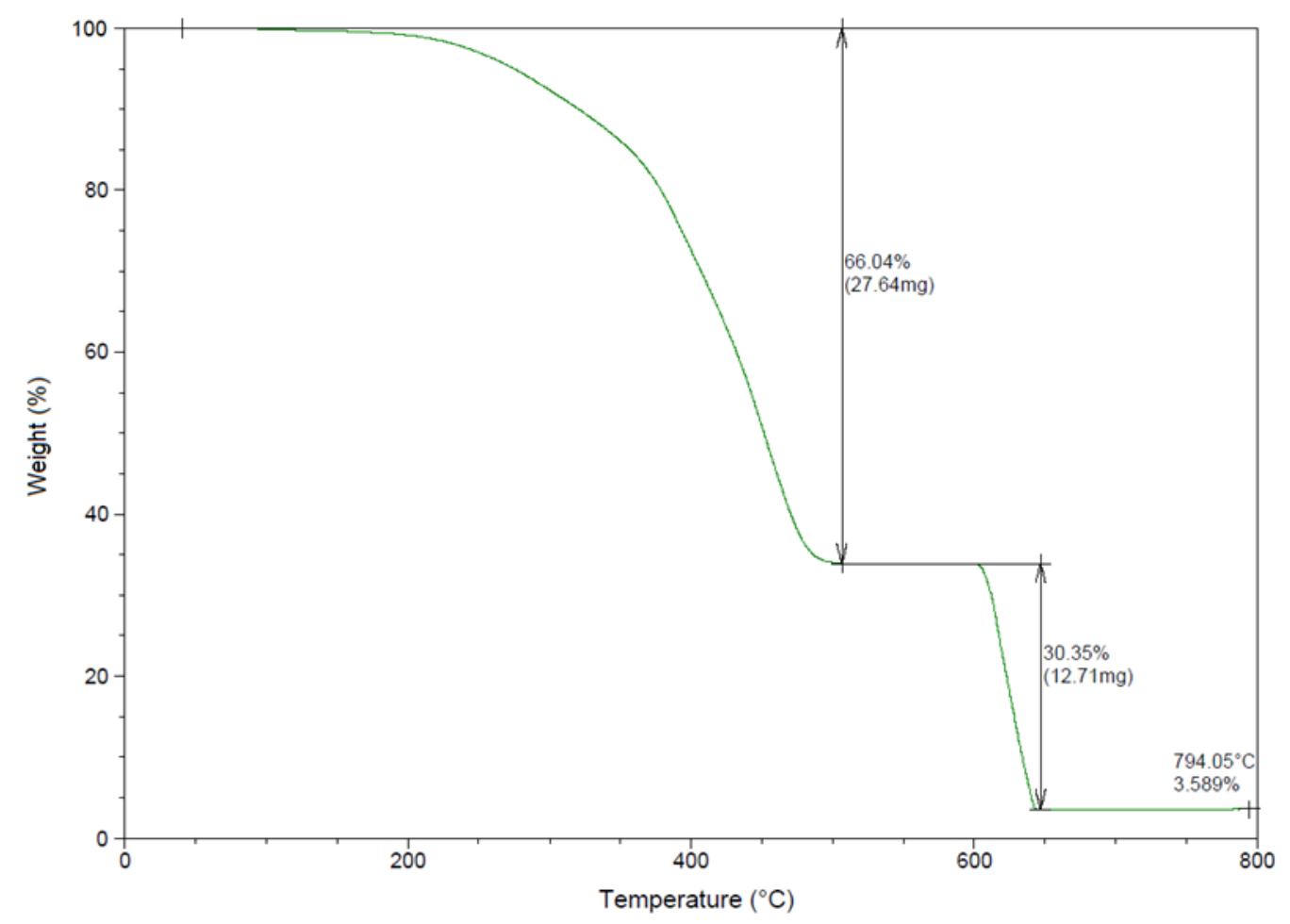

Şekil 11. K2 numunesinin termogramı 


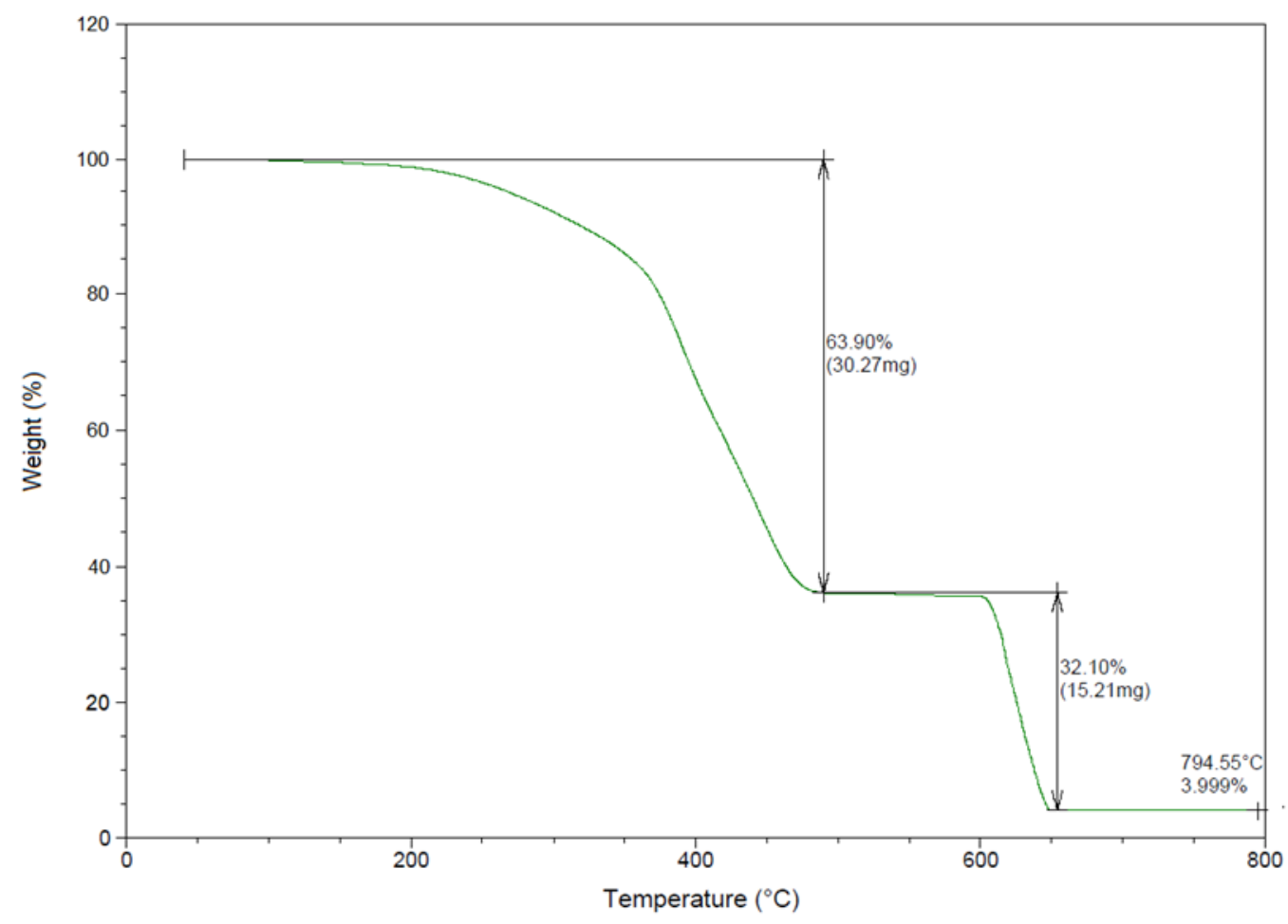

Şekil 12. K3 numunesinin termogramı

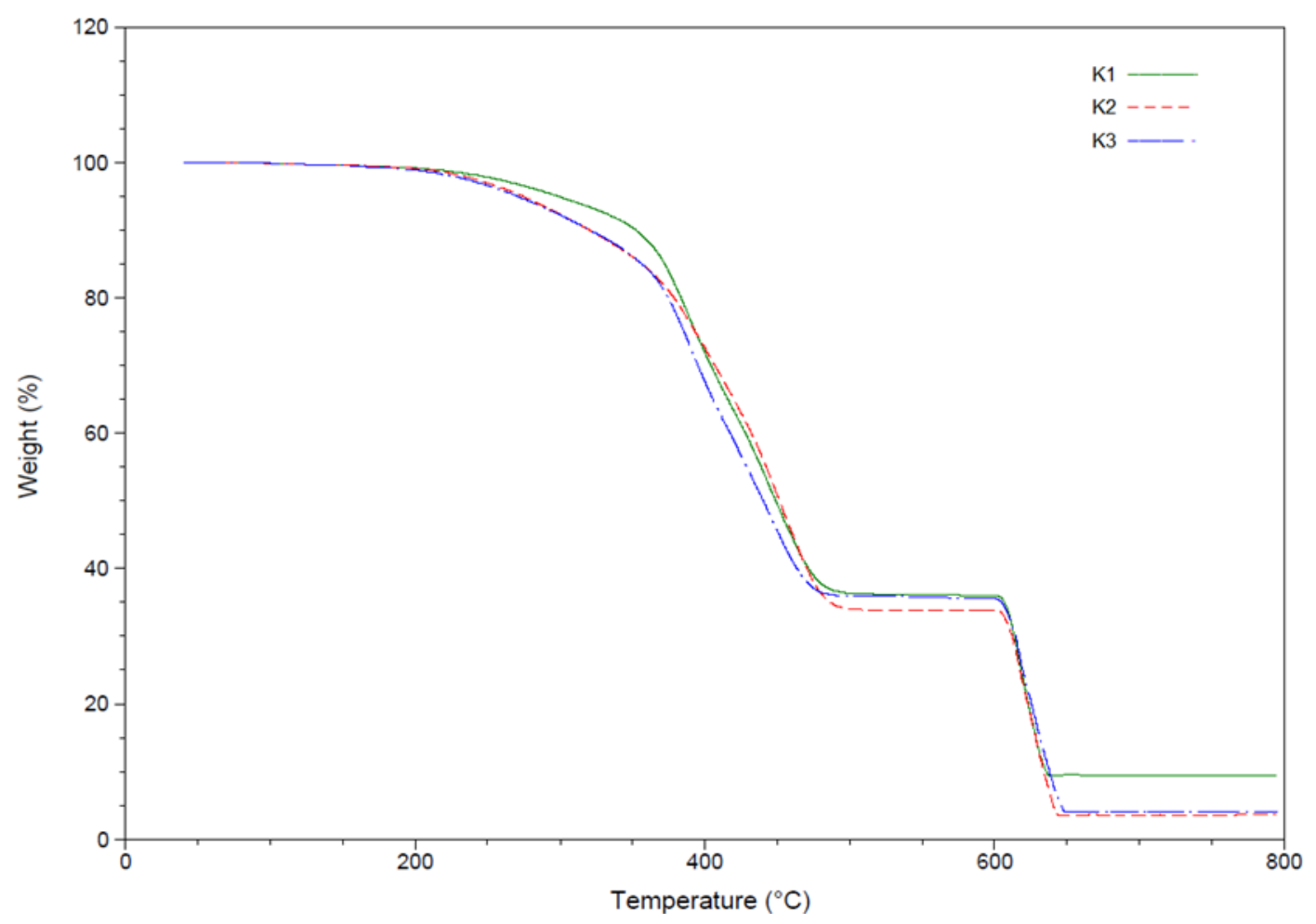

Şekil 13. K1, K2 ve K3 numunesinin termogramlarının beraber gösterimi 
Tablo 6. TGA analiz sonuçları.

\begin{tabular}{cccc}
\hline Numune & $\begin{array}{c}\text { Polimer + Yăg, } \\
(\%)\end{array}$ & $\begin{array}{c}\text { Karbon siyahı, } \\
(\%)\end{array}$ & $\begin{array}{c}\text { İnorganik madde, } \\
(\%)\end{array}$ \\
\hline K1 & 63,65 & 26,85 & 9,5 \\
\hline K2 & 66 & 30 & 4 \\
\hline K3 & 63,9 & 32,1 & 4 \\
\hline
\end{tabular}

Termogramların analiz sonuçları, Tablo 6'da gösterilmiştir. K2 ve K3 numenlerinin karbon siyahı ve inorganik madde miktarı yüzdelerinin yaklaşık olarak aynı olduğu görülmektedir. K1 numunesinde ölçülen \%9,5 inorganik madde miktarı, Tablo 1 'de belirtilen $10 \pm 1 \mathrm{phr}$ miktarındaki $\mathrm{CaCO}_{3}$ kullanımından kaynaklı olduğunu düşünülmektedir.

\section{IV.SONUCLAR}

Performans bisiklet lastiği sırt karışımından, kullanım sırasında yüksek performans gösterebilmesi için beklenen en önemli parametreler; hafif olması, kopma, uzama ve yırtılma dayanımlarının yüksek, modulus değerlerinin de düşük olmasıdır. Bu çalışmada elde edilen sonuçlar aşağıda özetlenmiştir.

- $\quad$ Seçilen karışım formülleriyle elde edilen K1, K2 ve K3 numunelerinin viskozite, yoğunluk ve sertlik değerleri birbirine yakındır.

- $\quad$ Üretim kolaylığı açısından; numunelerin viskozite ve t90 değerinin düşük, ts2 değerinin de yüksek olması istenmektedir. Bu bağlamda K1 numunesinin t90 değeri 51 saniye ile diğerlerine göre daha düşük olmasına rağmen, ts2 değeri nedeniyle karışımda yanık oluşturma ihtimali yüksektir. $\mathrm{Bu}$ veriler, diğer numunelerin kullanımını daha avantajlı kılmaktadır.

- $\quad$ TGA analizleri, K2 ve K3 karışımlarının yaklaşık aynı termal davranış1 gösterdiğini ve bu sonuçların Tablo 4 ve 5'te belirtilen diğer yöntemlerle elde edilen sonuçlarla aynı doğrultuda birbirini destekler nitelikte olduğunu göstermektedir.

- $\quad$ TGA analizlerinin, karışım bileşiminin aydınlatılması çalışmalarında etkili bir araç olarak kullanılabileceği birkez daha bu çalışma ile ortaya konulmuştur.

- $\quad \mathrm{K} 2$ ve K3 numunelerinin kopma dayanımı ve uzama yüzdesi K1 numunesine göre daha iyi olduğu görülmektedir. Modulus değeri K2'ye göre daha yüksek olan K3 numunesinin, yırtılma direncinin de yüksek olması nedeniyle daha uygun bir numune olarak performans lastiklerinde başarıyla kullanılabileceği anlaşılmaktadır.

TEȘEKKÜR: Bu çalışma TÜBİTAK 1501 (Proje No: 3180325) ve Düzce Üniversitesi Bilimsel Araştırma Projeleri (Proje No: 2018.06.05.875) tarafından desteklenmiştir. Bu çalışmada bizden desteklerini esirgemeyen ANLAS ANADOLU LASTIKK SAN. TİC. A.Ş. çalışanları; Leyla Ağan, Metin Kuru ve Levent Kahraman'a ve RPA verilerini incelemede çalışmamıza katkı sağlayan Yüksek Kimyager Yusuf Güner'e teşekkür ediyoruz. 


\section{KAYNAKLAR}

[1] H. Ritchie ve M. Roser. (2020) "Fossil Fuels" [Çevrimiçi]. Erişim Adresi: https://ourworldindata.org/fossil-fuels Erişim Tarihi: 13.03.2020

[2] H. Gerengi, A. Jazdzewska, ve M. Kurtay, "A Comprehensive Evaluation of Mimosa Extract as A Corrosion Inhibitor on AA6060 Alloy in Acid Rain Solution: Part I. Electrochemical AC Methods," J. Adhes. Sci. Technol, c. 29, ss. 36, 2015.

[3] H. Gerengi, P. Slepski, E. Ozgan ve M. Kurtay, "Investigation of Corrosion Behaviour of 6060 and 6082 Type Aluminum Alloys Under Simulated Acid Rain Conditions," Mater. Corros, c. 66, ss. 233, 2015.

[4] P. Zeppini ve J. C. J. M. van den Bergh, "Global Competition Dynamics of Fossil Fuels and Renewable Energy Under Climate Policies and Peak Oil: A Behavioural Model," Energy Policy, c. 136, ss. 110907, 2020.

[5] Anonim, (2020), "A partial list of products made from Petroleum” [Çevrimiçi]. Erişim Adresi: https://whgbetc.com/petro-products.pdf. Erişim Tarihi: 13.03.2020

[6] H. Gerengi ve H. Göksu, Plastik Malzeme Teknolojisi, Seçkin Yayıncılık, ISBN: 9789750252167, 45-60, ss. 2019.

[7] N. B. Hunga ve O. Lim, "A Review of History, Development, Design And Research Of Electric Bicycles,” Applied Energy, c. 260, ss. 114323, 2020.

[8] J.Y. Yong, V.K. Ramachandaramurthy, K.M. Tan ve N. A. Mithulananthan "Review on the State-of-the-Art Technologies of Electric Vehicle, Its Impacts and Prospects," Renew Sustain Energy Rev, c. 49, ss. 365-85, 2015.

[9] J. Brady ve M, O'Mahony, "Development of A Driving Cycle to Evaluate the Energy Economy of Electric Vehicles in Urban Areas," Appl Energy, c. 177, ss. 165-78, 2016.

[10] E. Çetin, H. Gerengi ve G. Altundal, "Delinmeye Karşı Dayanıklı Yüksek Performans Bisiklet Lastiğinin Geliştirilmesi," Uluslararası Akademik Araştırmalar Kongresi, Bolu, Türkiye, 2019, ss 441-458.

[11] C. Woodford, (2020) "The Science of Bicycles" [Çevrimiçi], Erişim Adresi: https://www.explainthatstuff.com/bicycles.html. Erişim Tarihi: 13.03.2020

[12] M. Riplogle, "Bicycle Access to Public Transportation: Learning From Abroad," Inst. Transport. Eng. J., ss. 15-21, 1992.

[13] P. Bazilinskyy, S. M. Petermeijer, V. Petrovych, D. Dodou ve J. C. F.de Winter, "Take-Over Requests in Highly Automated Driving: A Crowdsourcing Survey on Auditory, Vibrotactile, and Visual Displays," Transportation Research Part F, c. 56 ss. 82-98, 2018.

[14] U. Kapcak, E. Çetin, L. Kahraman ve H. Gerengi, "Bisiklet Lastiklerinde Surt Deseninin Performansa Etkisi," Zeugma II. Uluslararası Multidisipliner Çalı̧̧malar Kongresi, Gaziantep, Türkiye, 2019, ss. 650-665.

[15] E. Çetin, H. Gerengi ve G. Altundal, "Katlanabilir Özelliğe Sahip Yüksek Performans Bisiklet Lastiğinin Geliştirilmesi,” Bolu Uluslararası Akademik Araştırmalar Kongresi, Bolu, Türkiye, 2019, ss. $430-452$. 
[16] H. Gerengi, "Development of High Performance Bicycle Tire with Textile Heels," Duzce University, Duzce, Turkey, Project No: 2018.06.05.875.

[17] G. Altundal, "The Effect of Process Oils on NR/SBR Based Rubber Vehicle Tire Mixtures," Master Thesis, Institute of Science Department of Composite Material Technologies, Duzce University, Duzce, Turkey, May 2016.

[18] Standart Profil, (2019) [Çevrimiçi]. Erişim Adresi: https://www.standardprofil.com/ Erişim tarihi: 13.03 .2020

[19] S. D. Kucuk, H. Gerengi and Y. Guner, "The Effect of Tinuvin Derivatives as An Ultraviolet (UV) Stabilizer on EPDM Rubber," Periodicals of Engineering and Natural Sciences, c. 6, ss. 52-62, 2018.

[20] P. A. Ciullo, N. Hewitt, "The Rubber Formulary," Plastics Design Library, William Andrew, 1999, ss. 56-57. 